\title{
Genome-wide joint SNP and CNV analysis of aortic root diameter in African Americans: the HyperGEN study
}

\author{
Nathan E Wineinger ${ }^{1 *}$, Amit Patki ${ }^{1}$, Kristin J Meyers ${ }^{2}$, Ulrich Broeckel ${ }^{3}$, Charles C Gu${ }^{4}$, DC Rao ${ }^{4}$, Richard B Devereux ${ }^{5}$ \\ , Donna K Arnett ${ }^{6}$, Hemant K Tiwari ${ }^{1}$
}

\begin{abstract}
Background: Aortic root diameter is a clinically relevant trait due to its known relationship with the pathogenesis of aortic regurgitation and risk for aortic dissection. African Americans are an understudied population despite a particularly high burden of cardiovascular diseases. We report a genome-wide association study on aortic root diameter among African Americans enrolled in the HyperGEN study. We invoked a two-stage, mixed model procedure to jointly identify SNP allele and copy number variation effects.
\end{abstract}

Results: Results suggest novel genetic contributors along a large region between the CRCP and KCTD7 genes on chromosome $7\left(p=4.26 \times 10^{-7}\right)$; and the SIRPA and PDYN genes on chromosome $20\left(p=3.28 \times 10^{-8}\right)$.

Conclusions: The regions we discovered are candidates for future studies on cardiovascular outcomes, particularly in African Americans. The methods we employed can also provide an outline for genetic researchers interested in jointly testing SNP and CNV effects and/or applying mixed model procedures on a genome-wide scale.

\section{Background}

African Americans are known to be at increased risk for adverse cardiovascular outcomes including arterial stiffness and hypertension [1,2]. This observation makes African Americans a favorable population for genome-wide association studies (GWAS) on traits related to cardiovascular disease. The size of the aortic root is one such trait as it has been shown to play a major role in the pathogenesis of aortic regurgitation and risk for aortic dissection [3]. Enlargement of the aortic root has also been shown to be associated with arterial blood pressure in some studies [4-8] but not others [9] leading some investigators to hypothesize its role in the development of hypertension $[10,11]$. Despite reports of high heritability in common cardiovascular diseases, even large-scale GWAS have failed to replicate positive associations [12-14]. One possible explanation is that these complex diseases may be mediated by multiple pathophysiologic processes, such as enlargement of the aortic root, which

\footnotetext{
* Correspondence: nwineing@uab.edu

'Department of Biostatistics, University of Alabama at Birmingham, Birmingham, AL, USA

Full list of author information is available at the end of the article
}

are potentially better suited for disease-gene association testing. Previous studies have reported linkage between the diameter of the aortic root and candidate genes by using an extreme-values approach [15]; and in a genome scan [16]. A meta-analysis of GWAS results has identified genetic variants associated with the trait on chromosomes 5, 12p, 12q, and 17 [17]. However, only individuals of European ancestry were included.

The success of GWAS relies on the assumption that the heritability in common diseases can be captured by relatively few common genetic variants in the form of single nucleotide polymorphisms (SNPs) - sometimes referred to as the common disease, common variant hypothesis $[18,19]$. However, a substantial proportion of the heritability of many of these diseases remains left unexplained as traditional GWAS based upon SNPs have only accounted for a modest proportion of the total genetic variation. Among others, copy number variation (CNV) has been cited as a potential source of this so-called missing heritability [20].

Two recent studies have investigated the genomic architecture of CNVs in African Americans [21,22]. These reports suggest CNVs represent a significant

\section{Ciomed Central}


source of genetic variation in this population. We report the results from a non-traditional GWAS on aortic root diameter in African Americans which evaluated SNP and copy number effects simultaneously. We gathered phenotypic and genetic data on 1,086 family members enrolled in the HyperGEN study [23] who were genotyped on the Affymetrix 6.0 array. We obtained SNP and CNV calls from the Larry Bird application in Birdsuite software [24]; and performed a two-stage, mixed model procedure designed to identify SNP and CNV effects after controlling for potential confounders. We found two interesting signals: one stretching between the CRCP and KCTD7 genes on chromosome 7 and the other between the SIRPA and PDYN genes on chromosome 20.

\section{Methods}

Phenotypic data was obtained on 1,086 self-reported African American family members and individuals enrolled in the HyperGEN study [23]. HyperGEN is one of four Family Blood Pressure Program networks supported by the National Heart, Lung, and Blood Institute (NHLBI) to identify genetic contributors to hypertension. Subjects were recruited from centers located in Birmingham, AL and Forsyth County, NC. In the first recruitment phase of the HyperGEN study, hypertensive sibships eligible for recruitment consisted of probands with onset of hypertension by age 60 and one or more hypertensive siblings who were willing to participate in the study. In the second phase, the offspring of the hypertensive siblings were recruited. Hypertension was defined as an average systolic blood pressure $\geq 140 \mathrm{~mm} \mathrm{Hg}$ or an average diastolic blood pressure $\geq 90 \mathrm{~mm} \mathrm{Hg}$ during at least two evaluations, or receiving medical treatment for hypertension.

The present study cohort consisted of 421 families. Families varied in size from single individuals to larger families, up to 10 (Table 1). Measurements were recorded on age, gender, height, weight, body mass index, systolic blood pressure, diastolic blood pressure, and aortic root diameter (Table 2). Aortic root diameter measurements were performed during quiet respiration with twodimensional echocardiography. Aortic root was evaluated at end-diastole at the level of the aortic annulus and the sinuses of Valsalva in the long-axis view [25]. Measurements were made at Cornell Medical Center and verified by an experienced investigator. Further procedures for evaluating aortic root dimensions at the sinuses of Valsalva are described in Roman et al. [26,27]. This study was approved by the Institutional Review Board (IRB) and all subjects provided informed consent.

\section{Genotyping procedures}

Genetic data was obtained through the Affymetrix Genome-Wide Human SNP Array 6.0. Samples were grouped into 34 batches in which a batch consisted of
Table 1 Family structure of African American study participants enrolled in HyperGEN and genotyped on the Affymetrix 6.0 array

\begin{tabular}{ccc}
\hline Family size & Families & Individuals \\
\hline 1 & 99 & 99 \\
2 & 160 & 320 \\
3 & 69 & 207 \\
4 & 48 & 192 \\
5 & 23 & 115 \\
6 & 10 & 60 \\
7 & 8 & 56 \\
8 & 0 & 0 \\
9 & 3 & 27 \\
10 & 1 & 10 \\
\hline Total & 421 & 1,086 \\
\hline
\end{tabular}

all the samples that were processed on a particular day. The Affymetrix genotyping protocol was followed. Quality control was assessed using fifty control SNPs located on each array which were typed using a second independent platform (ABI Taqman). Genotype-based quality control was assessed by checking markers for Mendelian inconsistencies, potential patterns of missing data, and allele frequency measurements (Additional file 1, S1).

SNPs and CNVs were called using Birdsuite software, Version 1.5.5 [24]. Software parameters were kept at the developers' default values; and the Human Genome 18 reference build was used for probe localization. Samples were processed by batch to eliminate batch effects. This allows for better clustering of the data and improves sensitivity and specificity of the algorithm compared to combining data across batches [28]. The Larry Bird application within Birdsuite was used to generate CNVSNP genotypes at each locus. Larry Bird combines information on copy number segment calls using the HMM-

Table 2 Descriptive statistics of African American study participants enrolled in HyperGEN and genotyped on the Affymetrix 6.0 array

\begin{tabular}{lc}
\hline & $\mathbf{n}=\mathbf{1 , 0 8 6}$ \\
\hline Age (years) & $43.9 \pm 13.4$ \\
Females (\%) & 66.6 \\
Height $(\mathrm{cm})$ & $168.0 \pm 90.0$ \\
Weight $(\mathrm{kg})$ & $91.3 \pm 23.9$ \\
BMI (kg/m²) & $32.5 \pm 8.1$ \\
SBP (mmHg) & $128.9 \pm 22.2$ \\
DBP (mmHg) & $73.8 \pm 11.7$ \\
Center & \\
$\quad$ Birmingham, AL & 236 \\
$\quad$ Forsyth County, NC & $3.26 \pm 0.38$ \\
ARD (cm) &
\end{tabular}

Mean \pm standard deviation when applicable. BMI, body mass index; SBP, systolic blood pressure; DPB, diastolic blood pressure; ARD, aortic root diameter. 
based Birdseye, and SNP calls using the Birdseed applications within Birdsuite. The result is a more accurate depiction of locus-specific nucleotide frequency, particularly in non-diploid regions; and allows for the joint modeling of allelic and copy number effects at a given locus. Only calls with confidence values less than 0.1 were considered per the developers' recommendation (higher values indicate more uncertainty).

\section{Statistical analyses}

SNP and CNV joint tests of genetic association on the logarithm of aortic root diameter (AR2D) were conducted on all autosomal SNP marker loci genotyped on the Affymetrix 6.0 array that passed quality control thresholds (Additional file 1, S1). The joint test was performed following an approach similar to the model proposed by Korn et al. [24]. That is, at any particular locus containing SNP alleles labeled generically as A and B:

$$
\mathrm{Y}=\alpha+\beta_{1}(\mathrm{a}-\mathrm{b})+\beta_{2}(\mathrm{a}+\mathrm{b})+\varepsilon
$$

where $\mathrm{Y}$ represents the dependent variable of interest, $\mathrm{a}$ is the number of $\mathrm{A}$ alleles at the locus, $\mathrm{b}$ is the number of $\mathrm{B}$ alleles at the locus, $\beta_{1}$ corresponds to the additive SNP allele effect, and $\beta_{2}$ corresponds to the additive copy number effect. The joint test involves assessing the null hypothesis: $\beta_{1}=\beta_{2}=0$. When either SNP allele or copy number state is invariant, the model defaults to a single test of either allelic or copy number effect: $\beta_{1}=0$ or $\beta_{2}=0$, respectively.

The model described in equation $\{1\}$ can be manipulated to give investigators control over potential confounding factors by including them as covariates. Because the HyperGEN cohort includes family data, the model was altered into a mixed model by including random effects for each family. Furthermore, population stratification due to genetic admixture can confound population association studies or produce spurious results [29-32]. To account for this problem, the first four principal components were included in the model as fixed effects covariates [33]. The choice of four principal components was based on examination of the associated eigenvalues (Additional file 2, Table S1). Finally, age, age-squared, sex, and the recruitment center were included as additional fixed effects covariates. Thus, the full mixed model used for the analysis can be written as:

$$
\begin{aligned}
\ln (\text { AR2D })= & \alpha+\beta_{1}(\mathrm{a}-\mathrm{b})+\beta_{2}(\mathrm{a}+\mathrm{b}) \\
& +\sum_{j=1}^{4} \phi_{j}\left(\mathrm{PC}_{j}\right)+\phi_{5}(\text { Age }) \\
& +\phi_{6}\left(\mathrm{Age}^{2}\right)+\phi_{7}(\text { Sex }) \\
& +\phi_{8}(\text { Center })+\gamma_{i}(\text { Family })+\varepsilon
\end{aligned}
$$

where, in addition to the parameters described in $\{1\}$, $\varphi_{j}, \mathrm{j}=1, \ldots, 4$ are the fixed effects from the first four principal components, $\varphi_{5}, \varphi_{6}, \varphi_{7}, \varphi_{8}$ and are the fixed effects for age, age-squared, sex, and recruitment center, respectively, and $\gamma_{i}$ is the family random effect of the $i^{\text {th }}$ subject.

Fitting the mixed model described in equation $\{2\}$ for each SNP marker locus is currently infeasible without approximations [34]. Because of this limitation, a twostage procedure was enacted. In the first stage, a test of association using the GRAMMAR approach introduced by Aulchenko et al. [35] was used to determine the 1,000 most-likely significant markers. In the second stage, those 1,000 markers, referred to as the top 1,000, were tested using the full mixed model described in equation $\{2\}$. The GRAMMAR approach allows genomewide mixed model calculations to be computed on a reasonable timescale. As part of the procedure, model residuals for aortic root diameter measurements are generated via mixed model after controlling for relatedness and fixed effect covariates. However, genetic effects are not included. In terms of the present study:

$$
\begin{aligned}
\widehat{\varepsilon_{i}} & =\ln \left(\mathrm{AR}^{2} \mathrm{D}_{i}\right)-\widehat{\alpha}-\sum_{j=1}^{4} \widehat{\phi_{j}} \cdot \mathrm{PC}_{i, j} \\
& -\widehat{\phi_{5}} \cdot \mathrm{age}_{i}-\widehat{\phi_{6}} \cdot \mathrm{age}_{i}^{2}-\widehat{\phi_{7}} \cdot \operatorname{sex}_{\mathrm{i}} \\
& -\widehat{\phi_{8}} \cdot \operatorname{center}_{i}-\widehat{\gamma_{i}} \cdot \text { family }_{i} \\
& =\mathrm{Y}_{i}^{*}
\end{aligned}
$$

The resulting residuals $\left(\mathrm{Y}_{i}^{*}\right)$ for the $i^{\text {th }}$ subject are then regressed against his or her SNP allele and copy number state at each locus in a linear model:

$$
\mathrm{Y}^{*}=\alpha+\beta_{1}(\mathrm{a}-\mathrm{b})+\beta_{2}(\mathrm{a}+\mathrm{b})+\varepsilon .
$$

Residuals for use in the GRAMMAR approach were obtained from the PROC MIXED procedure in SAS ${ }^{\circledR}$ software, Version 9.1.2 (SAS Institute Inc., Cary, NC). The residuals were regressed on allelic and copy number state via $l m$ using $\mathrm{R}$ version 2.10.1 [36]. Genome-wide measurements were recorded (Figure 1). The markers corresponding to the 1,000 most-likely significant findings using this approach were recorded; and only these were analyzed in the full mixed model described in equation $\{2\}$, using the lmer function in $\mathrm{R}$ [37]. The most promising results are included in Table 3 and the second stage results from all loci in the top 1,000 are included in Additional file 3, Table S2. Genetic markers with $\mathrm{p}$-values less than $5 \times 10^{-7}$ were defined as genome-wide significant $[12,17]$. 


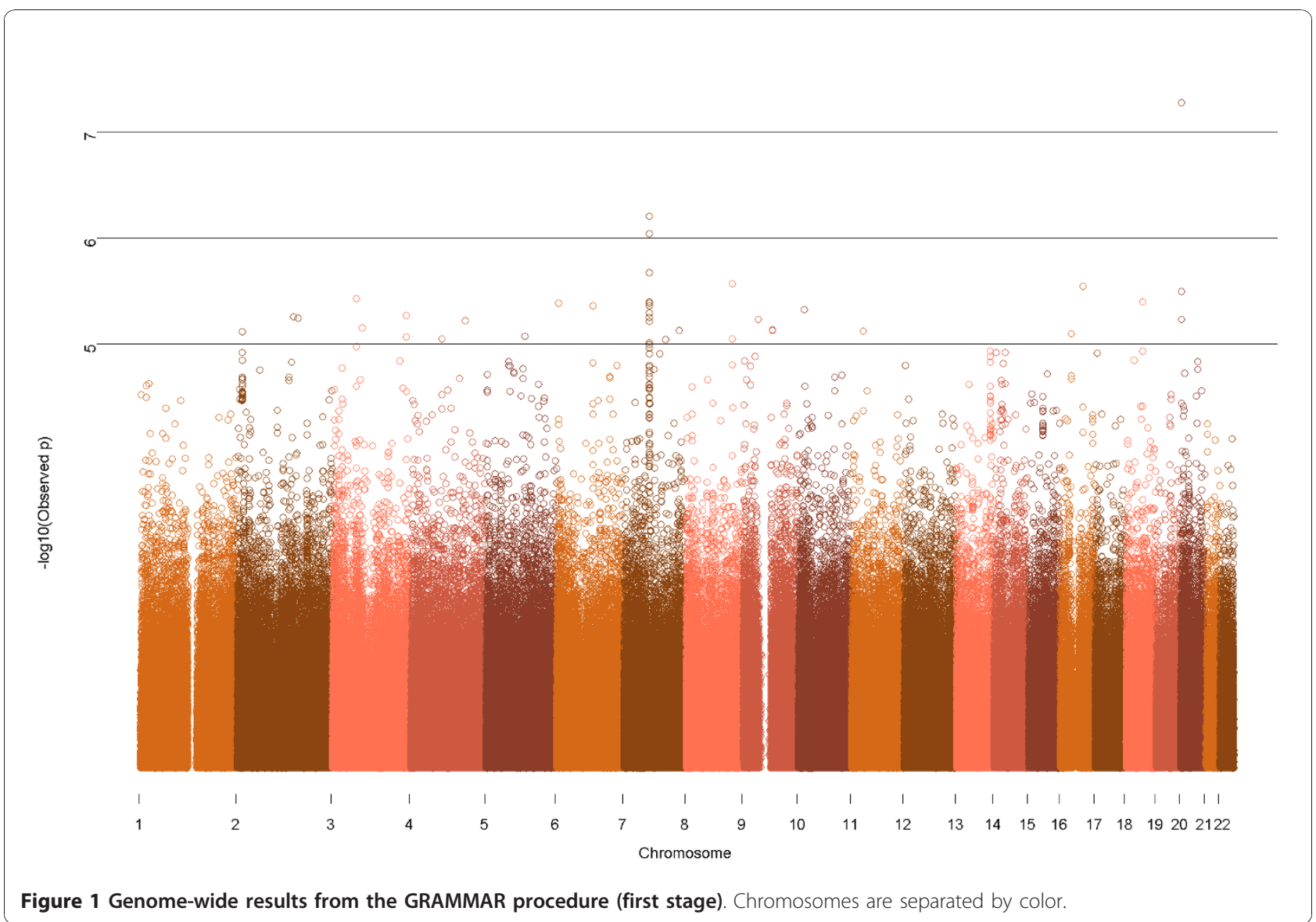

\section{Results and Discussion}

Genome-wide results were generated via a two-stage procedure (see Methods). The GRAMMAR procedure (first stage), alone, does not provide accurate parameter estimates and significance values. The systematic depression of the test statistic, which can be seen in the quantile-quantile (QQ) plot (Additional file 4, Figure S1), demonstrates that this method is inherently

Table 3 The top ten most significant markers from the first and second stages of the aortic root diameter genomewide association study

\begin{tabular}{|c|c|c|c|c|c|c|c|}
\hline \multirow[b]{2}{*}{ Chromosome } & \multirow[b]{2}{*}{ Base pair } & \multirow[b]{2}{*}{ Marker } & \multirow[b]{2}{*}{ MAF } & \multirow{2}{*}{$\begin{array}{l}\text { Stage } 1 \\
\text { p-value }\end{array}$} & \multicolumn{2}{|c|}{ Stage 2} & \multirow[b]{2}{*}{ Gene(s) } \\
\hline & & & & & SNP effect* & $p$-value & \\
\hline 3 & $59,877,841$ & rs1825630 & 0.444 & $3.70 \times 10^{-5}$ & $9.46(2.11)$ & $7.99 \times 10^{-6}$ & FHIT \\
\hline 7 & $65,255,030$ & rs875971 & 0.324 & $3.99 \times 10^{-5}$ & $10.69(2.24)$ & $4.09 \times 10^{-6}$ & $C R C P$ \\
\hline 7 & $65,668,047$ & rs801193 & 0.337 & $3.97 \times 10^{-5}$ & $11.13(2.23)$ & $3.65 \times 10^{-6}$ & LOC401365, LOC493754 \\
\hline 7 & $65,700,370$ & rs10258739 & 0.318 & $2.11 \times 10^{-5}$ & $10.64(2.26)$ & $2.50 \times 10^{-6}$ & \\
\hline 7 & $65,733,463$ & AFFX 9317457 & 0.332 & $6.24 \times 10^{-6}$ & $11.25(2.23)$ & $6.20 \times 10^{-7}$ & KCTD7, RABGEF1 \\
\hline 7 & $65,733,463$ & rs10263935 & 0.324 & $9.06 \times 10^{-6}$ & $11.42(2.28)$ & $4.26 \times 10^{-7}$ & KCTD7, RABGEF1 \\
\hline 7 & $65,790,536$ & rs2659915 & 0.334 & $4.10 \times 10^{-5}$ & $10.84(2.22)$ & $4.27 \times 10^{-6}$ & RABGEF1 \\
\hline 8 & $117,625,451$ & rs4876662 & 0.195 & $2.70 \times 10^{-5}$ & $13.17(2.58)$ & $2.23 \times 10^{-6}$ & \\
\hline 16 & $57,316,833$ & rs12600277 & 0.162 & $2.84 \times 10^{-5}$ & 13.99 (2.98) & $2.72 \times 10^{-6}$ & GOT2 \\
\hline 20 & $1,888,504$ & rs6045666 & 0.351 & $3.21 \times 10^{-5}$ & $12.58(2.26)$ & $2.97 \times 10^{-6}$ & SIRPA, PDYN + \\
\hline 20 & $1,889,171$ & rs6045676 & 0.356 & $5.31 \times 10^{-7}$ & $11.47(2.28)$ & $3.28 \times 10^{-8}$ & SIRPA, PDYN† \\
\hline
\end{tabular}

The markers at rs6045676 and rs 10263935 reach the threshold for genome-wide significance $\left(\mathrm{p}<5 \times 10^{-7}\right)$. The last column lists known genes and proteins of unknown function within $10 \mathrm{~kb}$ of the identified marker.

* The regression coefficients $\left(10^{-2}\right.$ scale) for the SNP effect in equation $\{2\}$ and its standard error (in parentheses) are included. Meanwhile, CNV effects are excluded due to the low observed CNV frequency at each marker $(<1 \%)$.

† These genes are outside the $10 \mathrm{~kb}$ restriction, yet still included. 
conservative. This finding agreed with published results [35]. Due to this limitation we implemented the GRAMMAR approach as a screening procedure. In this first stage, the top 1,000 loci were identified. These loci included all markers with p-values less than $2.5 \times 10^{-3}$. In general, these markers appeared to be uniform across the genome, with the exception of a few regions. Chromosome 7 , in particular, had numerous markers making it into the top 1,000. Many of these markers were found in a $500 \mathrm{~kb}$ region spanning the CRCP and KCTD7 genes. It should be noted that neither loci within genes previously found to be associated with thoracic aortic aneurysm (ACTA2, MYH11, TGFBR1, and TGFBR2), nor regions previously identified as being associated with aortic root size reached inclusion into the top 1,000 [17].

As the results from the GRAMMAR procedure, alone, are not conclusive, we re-analyzed the top 1,000 from the first stage using the full mixed model described in equation $\{2\}$. We identified two regions of significance: the strongest signal found between the SIRPA and $P D Y N$ genes on chromosome 20; and numerous signals within the $500 \mathrm{~kb}$ region on chromosome 7 highlighted in the first stage results. In total there were 24 marker loci with $\mathrm{p}$-values less than $1 \times 10^{-5}$. Many of these were located within the $500 \mathrm{~kb}$ region on chromosome 7 (Figure 2), but a few were found elsewhere (Table 3).

While the loci that reached or approached genomewide significance predominantly achieved that threshold based upon SNP effects, the second largest signal, found within the KCTD7 gene on chromosome 7, was influenced, in part, by a rare copy number variant (less than $1 \%)$. The copy number estimate at this locus was nearly three times its standard error. Also, a $40 \mathrm{~kb}$ copy number variable region on chromosome 2 within a gene gap between LPIN1 and TRIB2 genes showed relatively large copy number effect estimates - about four times its standard error. At this location, a rare deletion was correlated with higher aortic root diameter $\left(\mathrm{p}_{\mathrm{CNV}}=2.97 \times 10^{-5}\right)$.

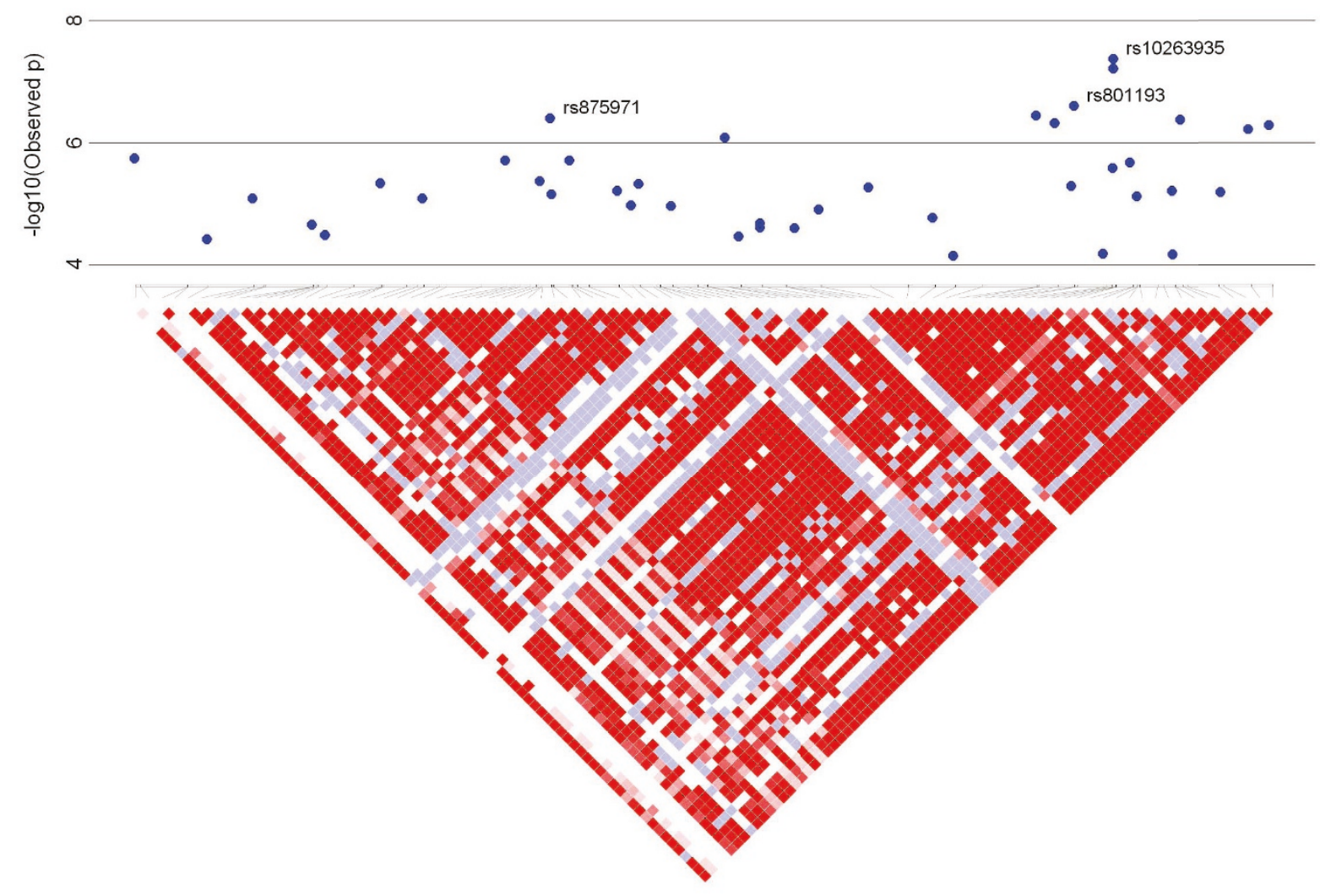

Figure 2 Inspection of significance peak on chromosome 7. Linkage disequilibrium measurements (below) overlaid with results from the full mixed model (second stage) on chromosome 7: 64,902,615 - 65,866,167 (above). 


\section{Conclusion}

African Americans have been disproportionately represented in genetic association studies on cardiovascular traits despite a well-documented high burden of cardiovascular diseases. We implemented a non-traditional statistical approach to test for genetic associations with aortic root diameter in African American family members enrolled in the HyperGEN study. This method allowed us to jointly test for SNP and CNV effect while controlling for family structure.

We identified two novel regions of genetic association on chromosomes 7 and 20. The significant SNPs in each region (rs10263935 and rs6045676, respectively) have different allele frequencies in YRI and CEU populations in HapMap [38] - providing a possible explanation why these associations have not been observed in previous studies based on populations of European descent [17]. The single strongest signal of genetic association was found on chromosome 20 between the SIRPA and $P D Y N$ genes. However, a clear relationship with either gene to cardiovascular traits beyond the results of this study has not been discovered. SIRPA is involved in negative regulation with numerous growth factor signaling receptors; and PDYN has been found to be associated with nonlesional temporal lobe epilepsy [39], but results have not been replicated [40]. Meanwhile, the much wider region identified on chromosome 7 contains an interesting gene that has been previously found to be related to cardiovascular outcomes: $C R C P$. The product of the $C R C P$ gene is known to interact with $C R L R$ to facilitate adrenomedullin (ADM) mediated signaling [41]. $C R L R$ has been found to be significantly decreased in the umbilical artery and uterus of women with pregnancy-induced hypertension [42]. Also, posttranslationally modified ADM has been known to influence vasodilation [43].

The two-stage procedure, joint analysis, and ascertainment scheme offered some limitations to the present study. First, it is possible that we missed a true association that did not pass the first stage criteria; but after comparing the results between the loci that were included in both steps, we are fairly comfortable as the results were consistent across stages. Only three of the top 1,000 did not have p-values less than $3 \times 10^{-3}$ in the second stage; and among the most significant findings, nine were in the top ten most significant findings in both stages. Second, the joint analyses we performed frequently reverted back to a conventional SNP analysis due to the majority of the genome being copy number invariant. However, we were cautious about using a SNP-only approach throughout the genome as it would require us to either treat non-two-copy genotypes as missing, or force them into a two-copy state.
And finally, the HyperGEN sib-pair ascertainment scheme restricted our ability to distinguish inherited copy number variation from variants arisen through de novo mutation as the direct transmission of CNVs from both parents to offspring was unobservable.

We found no findings that proved copy number variation was playing a role in the pathogenesis of aortic root diameter, but we do not believe CNVs should be ruled out altogether. In a few cases we found large estimates with promising significance values. Unfortunately, the low frequency of copy number events restricted our ability to separate their effects from more frequent SNPs. Also, copy number variants potentially cover numerous loci. In terms of copy number alone, we expect perfect or near-perfect linkage disequilibrium among those loci. Therefore, perhaps the same criteria imposed for genome-wide significance on SNPs should not hold for CNVs when looking at a "per locus" level.

Among those genes we identified as potentially influencing aortic root diameter, CRCP perhaps shows the most promise. However, the large region encompassing this gene shows strong patterns of linkage disequilibrium (Figure 2). Numerous other neighboring genes or loci could be influencing the result. Our other primary finding on chromosome 20 is curious as the flanking genes and reported expression results have not previously identified this region as contributing to cardiovascular outcomes. Nonetheless, future genetic studies on aortic root diameter and other related cardiovascular traits should consider the regions we identified as candidates.

\section{Additional material}

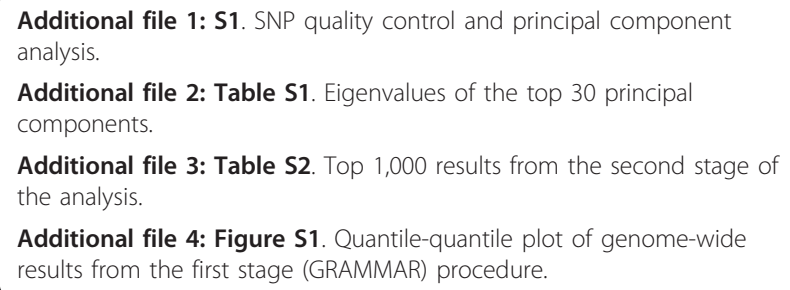

\section{Acknowledgements}

This study was supported in part by the Marie and Emmett Carmichael Scholarship, the NIH grants R01HL055673 and T32HL079888, and the Clinical and Translation Science Award program NIH grant 1UL1RR02011. The opinions expressed herein are those of the authors and not necessarily those of the $\mathrm{NIH}$ or any organization with which the authors are affiliated. This study was approved by the Institutional Review Board (IRB) and all subjects provided informed consent.

Author details

${ }^{1}$ Department of Biostatistics, University of Alabama at Birmingham, Birmingham, AL, USA. ${ }^{2}$ Department of Population Health Sciences, University 
of Wisconsin-Madison, Madison, WI, USA. ${ }^{3}$ Department of Pediatrics, Medical College of Wisconsin, Milwaulkee, WI, USA. ${ }^{4}$ Division of Biostatistics, Washington University, St. Louis, MO, USA. ${ }^{5}$ Division of Cardiology, Weill Cornell Medical College, New York, NY, USA. ${ }^{6}$ Department of Epidemiology, University of Alabama at Birmingham, Birmingham, AL, USA.

\section{Authors' contributions}

NEW obtained genotype calls from the processed data, performed the tests of association in both stages of the analysis, and prepared the manuscript. AP obtained principal components and was involved in database management. KJM performed tests of association on chromosome 7 on an independent dataset. UB converted raw data to processed genotypes. CCG $D C R, R B D$, and DKA are involved with the recruitment and upkeep of the HyperGEN cohort. HKT assisted in preparation of the manuscript. All authors read and approved the final manuscript.

\section{Competing interests}

The authors declare that they have no competing interests.

Received: 14 July 2010 Accepted: 11 January 2011

Published: 11 January 2011

\section{References}

1. American Heart Association. Heart disease and stroke statistics - 2009 Update [http://www.americanheart.org].

2. Sherva R, Miller MB, Lynch Al, Devereux RB, Rao DC, Oberman A, Hopkins PN, Kitzman DW, Atwood LD, Arnett DK: A whole genome scan for pulse pressure/stroke volume ratio in African Americans: the HyperGEN study. Am J Hypertens 2007, 20:398-402.

3. Roman MJ, Devereux RB, Niles NW, Hochreiter C, Kligfield P, Sato N, Spitzer MC, Borer JS: Aortic root dilation as a cause of isolated, severe aortic regurgitation. Prevalence, clinical and echocardiographic patterns, and relation to left ventricular hypertrophy and function. Ann Intern Med 1987, 106:800-807.

4. Vasan RS, Larson MG, Levy D: Determinants of echocardiographic aortic root size. The Framingham Heart Study. Circulation 1995, 91:734-740.

5. Jondeau G, Boutouyrie P, Lacolley P, Laloux B, Dubourg O, Bourdarias JP, Laurent $\mathrm{S}$ : Central pulse pressure is a major determinant of ascending aorta dilation in Marfan syndrome. Circulation 1999, 99:2677-2681.

6. Palmieri V, Bella JN, Arnett DK, Roman MJ, Oberman A, Kitzman DW, Hopkins PN, Paranicas M, Rao DC, Devereux RB: Aortic root dilatation at sinuses of Valsalva and aortic regurgitation in hypertensive and normotensive subjects: the Hypertension Genetic Epidemiology Network Study. Hypertension 2001, 37:1229-1235.

7. Farasat SM, Morrell CH, Scuteri A, Ting CT, Yin FC, Spurgeon HA, Chen $\mathrm{CH}$, Lakatta EG, Najjar SS: Pulse pressure is inversely related to aortic root diameter implications for the pathogenesis of systolic hypertension. Hypertension 2008, 51:196-202.

8. Ingelsson E, Pencina MJ, Levy D, Aragam J, Mitchell GF, Benjamin EJ, Vasan RS: Aortic Root Diameter and longitudinal blood pressure tracking. Hypertension 2008, 52:473-477.

9. Kim M, Roman MJ, Cavallini MC, Schwartz JE, Pickering TG, Devereux RB: Effect of hypertension on aortic root size and prevalence of aortic regurgitation. Hypertension 1996, 28:47-52.

10. Cuspidi C, Meani S, Valerio C, Esposito A, Sala C, Maisaidi M, Zanchetti A, Mancia G: Ambulatory blood pressure, target organ damage and aortic root size in never-treated essential hypertensive patients. J Hum Hypertens 2007, 21:531-538.

11. Mitchell GF: Impedance progress: aortic diameter rears its head again? Hypertension 2007, 49:1207-1209.

12. Wellcome Trust Case Control Consortium: Genome-wide association study of 14,000 cases of seven common diseases and 3,000 shared controls. Nature 2007, 447:661-678.

13. Ehret GB, Morrison AC, O'Connor AA, Grove ML, Baird L, Schwander K, Weder A, Cooper RS, Rao DC, Hunt SC, Boerwinkle E, Chakravarti A: Replication of the Wellcome Trust genome-wide association study of essential hypertension: the Family Blood Pressure Program. Eur I Hum Genet 2008, 16:1507-1511.

14. Hong KW, Jin HS, Cho YS, Lee JY, Lee JE, Cho NH, Shin C, Lee SH, Park HK, Oh B: Replication of the Wellcome Trust genome-wide association study on essential hypertension in a Korean population. Hypertens Res 2009, 32:570-574.

15. Arnett DK, Devereux RB, Rao DC, Li N, Tang W, Kraemer R, Claas SA, Leon JM, Broeckel U: Novel genetic variants contributing to left ventricular hypertrophy: the HyperGEN study. J Hypertens 2009, 27:1585-1593.

16. Vasan RS, Larson MG, Aragam J, Wang TJ, Mitchell GF, Kathiresan S, Newton-Cheh C, Vita JA, Keyes MJ, O'Donnell CJ, Levy D, Benjamin EJ: Genome-wide association of echocardiographic dimensions, brachial artery endothelial function and treadmill exercise responses in the Framingham Heart Study. BMC Med Genet 2007, 8(Suppl 1):S2.

17. Vasan RS, Glazer NL, Felix JF, Lieb W, Wild PS, Felix SB, Watzinger N, Larson MG, Smith NL, Dehghan A, Grosshennig A, Schillert A, Teumer A, Schmidt R, Kathiresan S, Lumley T, Aulchenko YS, König IR, Zeller T, Homuth G, Struchalin M, Aragam J, Bis JC, Rivadeneira F, Erdmann J, Schnabel RB, Dörr M, Zweiker R, Lind L, Rodeheffer RJ, Greiser KH, Levy D, Haritunians T, Deckers JW, Stritzke J, Lackner K, Völker U, Ingelsson E, Kullo I, Haerting J, O'Donnell CJ, Heckbert SR, Stricker BH, Ziegler A, Reffelmann T, Redfield MM, Werdan K, Mitchell GF, Rice K, Arnett DK, Hofman A, Gottdiener JS, Uitterlinden AG, Meitinger T, Blettner M, Friedrich N, Wang TJ, Psaty BM, van Duijn CM, Wichmann HE, Munzel TF, Kroemer HK, Benjamin EJ, Rotter Jl, Witteman JC, Schunkert H, Schmidt H, Völzke H, Blankenberg S: Genetic variants associated with cardiac structure and function: a meta-analysis and replication of genome-wide association data. JAMA 2009, 302:168-178.

18. Reich DE, Lander ES: On the allelic spectrum of human disease. Trends Genet 2001, 17:502-510.

19. Wang WY, Barratt BJ, Clayton DG, Todd JA: Genome-wide association studies: theoretical and practical concerns. Nat Rev Genet 2005, 6:109-118.

20. Manolio TA, Collins FS, Cox NJ, Goldstein DB, Hindorff LA, Hunter DJ, McCarthy MI, Ramos EM, Cardon LR, Chakravarti A, Cho JH, Guttmacher AE, Kong A, Kruglyak L, Mardis E, Rotimi CN, Slatkin M, Valle D, Whittemore AS, Boehnke M, Clark AG, Eichler EE, Gibson G, Haines JL, Mackay TF, McCarroll SA, Visscher PM: Finding the missing heritability of complex diseases. Nature 2009, 461:747-753.

21. Conrad DF, Pinto D, Redon R, Feuk L, Gokcumen O, Zhang Y, Aerts J, Andrews TD, Barnes C, Campbell P, Fitzgerald T, Hu M, Ihm CH, Kristiansson K, Macarthur DG, Macdonald JR, Onyiah I, Pang AW, Robson S, Stirrups K, Valsesia A, Walter K, Wei J, The Wellcome Trust Case Control Consortium, Tyler-Smith C, Carter NP, Lee C, Scherer SW, Hurles ME: Origins and functional impact of copy number variation in the human genome. Nature 2010, 464:704-712.

22. McElroy JP, Nelson MR, Cailler SJ, Oksenber JR: Copy number variation in African Americans. BMC Genet 2009, 10:15.

23. Williams RR, Rao DC, Ellison RC, Arnett DK, Heiss G, Oberman A, Eckfeldt JH, Leppert MF, Province MA, Mockrin SC, Hunt SC: NHLBI family blood pressure program: methodology and recruitment in the HyperGEN network. Hypertension genetic epidemiology network. Ann Epidemiol 2000, 10:389-400.

24. Korn JM, Kuruvilla FG, McCarroll SA, Wysoker A, Nemesh J, Cawley S, Hubbell E, Veitch J, Collins PJ, Darvishi K, Lee C, Nizzari MM, Gabriel SB, Purcell S, Daly MJ, Altshuler D: Integrated genotype calling and association analysis of SNPs, common copy number polymorphisms and rare CNVs. Nat Genet 2008, 40:1253-1260.

25. Lynch Al, Arnett DK, Atwood LD, Devereux RB, Kitzman DW, Hopkins PN, Oberman A, Rao DC: A genome scan for linkage with aortic root diameter in hypertensive African Americans and whites in the Hypertension Genetic Epidemiology Network (HyperGEN) study. Am J Hypertens 2005, 18:627-632.

26. Roman MJ, Devereux RB, Kramer-Fox R, O'Loughlin J: Twodimensional echocardiographic aortic root dimensions in normal children and adults. Am J Cardiol 1989, 64:507-512.

27. Roman MJ, Rosen SE, Kramer-Fox R, Devereux RB: Prognostic significance of the pattern of aortic root dilation in the Marfan syndrome. J Am Coll Cardiol 1993, 22:1470-1476.

28. Leek JT, Scharpf RB, Bravo HC, Simcha D, Langmead B, Johnson WE, Geman D, Baggerly K, Irizarry RA: Tackling the widespread and critical impact of batch effects in high-throughput data. Nat Rev Genet 2010, 11:733-379.

29. Ewens WJ, Spielman RS: The transmission/disequilibrium test: history, subdivision, and admixture. Am J Hum Genet 1995, 57:455-464. 
30. Deng HW: Population admixture may appear to mask, change or reverse genetic effects of genes underlying complex traits. Genetics 2001 159:1319-1323.

31. Halder I, Shriver MD: Measuring and using admixtre to study the genetics of complex diseases. Hum Genomics 2003, 1:52-62.

32. Hoggard CJ, Parra EJ, Shriver MD, Bonilla C, Kittles RA, Clayton DG, McKeigue PM: Control of confounding of genetic associations in stratified populations. Am J Hum Genet 2003, 72:1492-1504.

33. Price $A L$, Patterson NJ, Plenge RM, Weinblatt ME, Shadick NA, Reich D: Principal component analysis corrects for stratification in genome-wide association studies. Nat Genet 2006, 38:904-909.

34. Zhang Z, Ersoz E, Lai CQ, Todhunter RJ, Tiwari HK, Gore MA, Bradbury PJ, Yu J, Arnett DK, Ordovas JM, Buckler ES: Mixed linear model approach adapted for genome-wide association studies. Nat Genet 2010, 42:355-360.

35. Aulchenko YS, de Koning DJ, Haley C: Genomewide rapid association using mixed model and regression: a fast and simple method for genomewide pedigree-based quantitative trait loci association analysis. Genetics 2007, 177:577-585.

36. R Development Core Team: R: A Lanquage and Environment for Statistical Computing R Foundation for Statistical Computing, Vienna, Austria; 2009 [http://www.R-project.org], ISBN 3-900051-07-0.

37. Bates D, Maechler M, Dai B: Ime4: linear mixed-effects models using S4 classes 2008 [http://Ime4.r-forge.r-project.org], R package version 0.999375-28.

38. International HapMap Consortium: A haplotype map of the human genome. Nature 2005, 437:1299-1320.

39. Stögmann E, Zimprich A, Baumgartner C, Aull-Watschinger S, Höllt V, Zimprich $\mathrm{F}$ : A functional polymorphism in the prodynorphin gene promotor is associated with temporal lobe epilepsy. Ann Neurol 2002 51:260-263.

40. Tilgen N, Rebstock J, Horvath S, Propping P, Elger CE, Heils A: Prodynorphin gene promoter polymorphism and temporal lobe epilepsy. Ann Neurol 2003, 53:280-281.

41. Evans BN, Rosenblatt MI, Mnayer LO, Oliver KR, Dickerson IM: CGRP-RCP, a novel protein required for signal transduction at calcitonin gene-related peptide and adrenomedullin receptors. J Biol Chem 2000, 275:31438-31443.

42. Makino Y, Shibata K, Makino I, Kangawa K, Kawarabayashi T: Alteration of the adrenomedullin receptor components gene expression associated with the blood pressure in pregnancy-induced hypertension. J Clin Endocrinol Metab 2001, 86:5079-5082.

43. Fernández AP, Serrano J, Tessarollo L, Cuttitta F, Martínez A: Lack of adrenomedullin in the mouse brain results in behavioral changes, anxiety, and lower survival under stress conditions. Proc Natl Acad Sci USA 2008, 105:12581-12586.

\section{Pre-publication history}

The pre-publication history for this paper can be accessed here: http://www.biomedcentral.com/1755-8794/4/4/prepub

\section{doi:10.1186/1755-8794-4-4}

Cite this article as: Wineinger et al:: Genome-wide joint SNP and CNV analysis of aortic root diameter in African Americans: the HyperGEN study. BMC Medical Genomics 2011 4:4.

\section{Submit your next manuscript to BioMed Central and take full advantage of:}

- Convenient online submission

- Thorough peer review

- No space constraints or color figure charges

- Immediate publication on acceptance

- Inclusion in PubMed, CAS, Scopus and Google Scholar

- Research which is freely available for redistribution 